\title{
On the Translation of Literary Quotation in English Literary Works
}

\author{
Hongjuan Li \\ Tianjin Maritime College Tianjin, China, 300350
}

\begin{abstract}
Keywords: English literary works; Allusion; Translation method
\end{abstract}
\begin{abstract}
Allusions in English literary works in bring readers interest also bring translators more difficult, because English is a foreign language, it and the related ethnic culture is closely related to the background, representing the essence and the accumulation of a national culture, the language expression way and color are quite different from Chinese, which in the process of translation requires the translator to have a certain understanding of language contains the culture to translate lively place. This paper analyzes the translation methods and techniques of allusion translation in English literary works, in order to provide reference and guidance for translation work.
\end{abstract}

\section{Introduction}

The allusion is often appearing in all literature, vivid and interesting which often add works. In English literary works, too, and the use of high frequency, but allusions in the process of translation to the translator bring greater difficulties, because the allusion expression language is different from Chinese, which contains a nation's history, famous celebrities, fables, especially with the myths and legends, the nation's hundreds of thousands of years of historical and cultural heritage inseparable, if there is no good grasp of the cultural background, it is difficult to translate accurate and vivid. In addition, allusions to express with words with dialect and ancient, different from modern English and its rhetorical methods also in comparison to the classical to want to reflect the original artistic conception, it is necessary for the high translation skills.

\section{On the Sources of Common Literary References in English Literary Works}

Generally speaking, there are three main sources of literary allusion in English literary works, which can only be improved by the understanding of these sources.

The first kind of story comes from the fairy tale. This kind of literary quotation is the most common in English literary works, because the myth is considered to be the source of culture in the western culture, which represents the simplicity of the western thinking. In the view of the west, the plot and the characters in the myth are the people who are yearning and reverence, which reflects the psychological characteristics of the nation. For example, the apple of discord in the English allusions as is known to all, it is originated from apple in the ancient Greek myth story, describing the dispute. It is used to express people's yearning for peace and the dispute antipathy. For example, rain cats and dogs is actually the Nordic myth and its relationship to cat and weather will cat metaphor for the storm, and the dog metaphor for rain after the hurricane. Thus, after translation means "downpour".

Second types of allusions from historical stories, this kind of story is also very common. In the history of human development, are many changes occur every day, the historical story today can be regarded as the coordinates of civilization. History and culture are inseparable, literary works cited in historical allusions can not only enhance the literature, also can arouse the reader's interest. For example, the American literary works often appear water gate, if the literal translation, translated as "Watergate", its meaning or not distinctly. If you understand the history of the United States, you will know the phrase is specified on power abuse and fraud, and inevitably involved in the scandal, so this story is that in order to achieve the purpose of the means or illegal act. For example, the sentence deal with in a covert or criminal manner to be the best explanation for this story, and the use of this story in today's English literary works will be added to the suffix, the expression of "ugly". 
Third types of allusions originating from folk stories and legends. As Chinese literature, folk tales of great literary value in literature cited is common, because the regional customs it is can't be replaced other forms of literature. For example, a bird of ill omen the allusions, originally is an informal divination activities, because some bird's sense of smell is very sensitive, capable of far outside the body was discovered in a unique way, so people habit will this bird as representative of death. In addition, a feather in your cap is generally translated as "honor", this is because in the Indian tradition, if a person kills the enemy, can put the feathers on the head to show the glory. In the eyes of stocks, the bull market is a rise in the stock market, has been synonymous with the same, the British writer's novel, in the description of the stock market, the use of point bulls, but also refers to the state of the bull market.

The fourth kind of allusion is a unique source of allusion in the western literature, which is derived from the religious culture, especially from the "Bible". Because the Bible is regarded as the greatest western literature, it is easy to understand the story from other literary works. "The Bible" it is self-evident influence on ancient Western writers and readers, therefore also affects many western literary and cultural value orientation and style theme. For example, wash one's hands off can be translated into "Jinpen wash" [1]. This is because the Bible has a story tells of a Jew in of the trial of Jesus, Jesus sentenced for acquittal, Jewish people said the decision, so the judge said he is willing to listen to the opinions of the masses, and handed Jesus over to the disposal of the masses, to show himself and is no longer the case implicated., of course, in addition to the "Bible" in the story cited allusions, there are some classic literary works in the story is referenced by other literary works example, will not repeat them here.

\section{The Influence Factors of Literary Allusion Translation in English Literary Works}

Because of the long history of Chinese and western natural customs, cultural tradition, living habits, historical origins are very different, so in the Western way of thinking is also very different. This is reflected in the translation, often because of cultural background, education habits, religious beliefs and other different to the original reading does not understand or read. In the translation of English literary works, the first need to fully understand the relevant background, combined with western history and cultural origins, considering the western thinking and habits of life, the original works of a thorough interpretation. This is not enough to translated works, to be translated in English literary works perfectly presented to Chinese readers, but also taking into account the culture and living habits of the Chinese readers. In the most popular, most likely to receive and understand the language structures between the original and the translation smooth bridge beam.

Also, translators have to have sufficient capacity in the western literary allusions and the corresponding convergence, such as mentioned above in "cats and dogs". Of course, although the requirements are good at convergence, but also to grasp the differences, cannot be arbitrarily corresponding. For example, there is a story is burn one 's boat, in western culture, it is through the Silk Road on the sea, invade other generals after coming ashore will all aboard ships burned out, to soldiers alert everyone has no retreat, must Beishuiyizhan. This drastic means similar to those in traditional Chinese stories, but accurate to say or point difference, cannot be considered completely communicated with each other.

\section{On the Translation of Literary Quotations in English Literary Works}

There are four approaches to the translation of literary allusion in English literary works.

The first is literal translation. This is a translation in widespread adoption, direct and regulate translation habits, basic guarantee does not change the original meaning, in allusion translation, the allusions in the meaning of complete translation, not to join the other modification changes the original cultural elements and national colors. Literal translation does not mean mechanically, but according to the translation of allusions are more intuitive and originality principle. For example, they were only crying crocodile tears at the old man's funeral because nobody had really liked him. This sentence can be translated as "the old man's funeral people's tears are just crocodile tears bale, 
because no one really liked him". This translation is clear at a glance, the reader can also feel the vivid.

The second kind is the abstract translation method. This is a method of abstract translation of specific phrases or sentences, based on the cultural background of the differences, the results of this translation method often have very different. For example, is very cruel and considered as a dragon. He if the use of literal translation, the resulting should be "he is very cruel, is considered a dragon". Actually, in the eyes of the Chinese readers, the dragon is auspicious symbol, with the commendatory, practical English in the dragon and the meaning of different, it in Roman mythology is refers to a kind of demon, represents evil, often use the metaphor of nefarious. So here can abstract for devils and other means.

The third method is to use the translation method. As is analyzed in the above, some English allusion expressions are similar to the meaning of Chinese allusion, which can be translated into Chinese more easily accepted by Chinese readers. For example, Mr.Smith encouraged the workers to go on strike in order to fish in troubled waters this sentence can be in the second half of the sentence is "fish in troubled waters", that took advantage of the chaotic situation obtain their own interests.

The fourth kind is the free translation method, which is usually considered as the highest level of translation. When will destroy the original literal meaning or allusion and artistic conception, cannot use the translation, translation requires the translator. The effect of free translation is better when the adaptation to translation is reasonable. For example, in English translation, translation "the dog's mouth spit out of ivory", if the use of literal translation will get no ivory can come out of a dog 's mouth, this is very awkward, through the translation, can be translated into a filthy mouth cannot utter decent language, so the reader to read also feel more comfortable.

The last one is the combination of literal translation and annotation. For example, some English proverbs will involve allusions in the personal and place names, while tacit these proverbs, but translation if the notes will be better or readers tend to have abrupt feeling. For example, see Naples and die, if only literal translation, translated into "see Naples after death", the reader if you don't know what is Naples, confused, at this point in the process of translation notes, indicate Naples is Italy a southern port city, known as the wind Jing Xiumei, then the meaning of the sentence is very obvious the.

When it comes to the translation techniques of literary allusion in English literary works, first of all, it should follow the guidelines of "faithfulness, expressiveness and elegance", which is the same with all forms of translation. On the basis of the above four methods, it can be used to accurately figure out the allusion in English literary works.

For example, in translation "meet one 's Waterloo", literal translation "in case of someone's Waterloo", when the understanding of the source of allusions, understand that this is saying Lan Xi Emperor Napoleon in the place of Waterloo suffered defeat after end story of political career. In translation, can be translated as "fiasco". Again, for example, "Aesop's Fables" a story from a dog in the manger, in fact, is a pejorative, its original intention is said a dog in the manger, not to come to graze his position, but he himself doesn't eat grass. The allusion is "themselves unable to enjoy but don't let people enjoy the people, according to the Chinese proverb is occupied the manger.

In fact, the greatest difficulty in English literary works is to ensure that the original is not distorted. If we want to translate English allusion properly, we must first have a large amount of Western cultural background, traditional and historical accumulation. With the continuous integration of Chinese and Western culture, cultural differences are decreasing and the reader's cognition and values are also consistent, in some degree, it is beneficial to the translation work. As long as the proper use of the above translation methods, combined with their own accumulated knowledge, will be able to translate outstanding works.

\section{References}

[1] $\mathrm{Xu}$ yl. contrastive linguistics [M] Shanghai: Shanghai foreign language education press, 
2012:202-205

[2] HanidayM AK, The Linguistic Sciences and Language would [M]. London: Longman Greenand CoLtd, 2013:126-129.

[3] Wu Qin. Analyses the safety management of small and medium-sized enterprise office LAN [J]. Computer CD software and applications, 2012, 22:159+161.

[4] YanYanHua. Office LAN construction, maintenance and safety analysis [J]. China's new communications, 2011, 12:84-91.

[5] Sun Li, zhi-bo ma, zhang yi. Basis of maritime English tutorial [M]. Dalian: dalian maritime university press, 2012:149-151.

[6] Yang FengNing. Comparison and translation between English and Chinese language [M]. Tianjin: tianjin university press, 2012:136-138.

[7] Zhao Xuan, zheng Yang. English translation of science and technology [M]. Beijing: foreign language teaching and research press, 2013:405-406.

[8] Huang jing. maritime English translation problems [J]. Journal of Shanghai maritime university, 2012, 29 (12): 391-392.

[9] Cao Xiaoan. Skopos theory under the view. 